\title{
Initiatives Management's Role in Improving Work Efficiency: A Field Study On Workers in Salalah Methanol Company in Dhofar Governorate
}

\author{
Abubakar Ahmed Mohammed Almuallam, Mohammed Nashief S. Disomimba* \\ Faculty of Leadership and Management, Islamic Science University of Malaysia (USIM), Negeri Sembilan, \\ Malaysia \\ * mohammadnashief@usim.edu.my
}

\begin{tabular}{ll}
\hline KEYWORDS: & Management, Initiatives, Work Efficiency. \\
Crossref doi & https://doi.org/10.51345/.v32i3.448.g234 \\
\hline
\end{tabular}

\begin{abstract}
:
This quantitative study discussed the role of initiatives management in improving the work efficiency of the employees of the Methanol Company in the Dhofar Governorate in the Sultanate of Oman. The problem emerged that some Omani institutions suffered from administrative and economic crises as a result of fluctuations in oil prices, the absence of scientific bases adopted in the selection and appointment of people to jobs, and the absence of criteria for evaluating achievement and results. Therefore, the study aimed to; Diagnosing the level of initiatives management at the Methanol Company in the Dhofar Governorate, and the level of improving the company's work efficiency The study adopted the descriptive analytical approach, and the study population consisted of all employees of the Salalah Methanol Company in the Governorate of Dhofar, who numbered (160) employees. A random sample of (113) employees was selected according to the table of Gresty and Morgan (1970). The researcher designed a questionnaire by making use of the theoretical literature. It consisted of (48) phrases distributed in (8) axes. The following statistical methods were adopted: descriptive analysis, Pearson correlation coefficient, alpha consistency coefficient, T-test for two independent samples, oneway analysis of variance, multiple regression analysis, Scheffe test for dimensional comparisons. The research found a set of results, including: There is a direct relationship between initiatives management and improving work efficiency. There is a statistically significant effect at the level of significance $(\mathrm{a} \leq$ $0.05)$ between managing initiatives and improving work efficiency. There were no statistically significant differences at the level of significance $(\mathrm{a} \leq 0.05)$ about managing initiatives and improving work efficiency due to demographic variables.
\end{abstract}


إدارة المبادرات ودورها في تحسين كفاءة العمل: دراسة ميدانية على العاملين في شركة صلالة للميثانول في محافظة ظفار

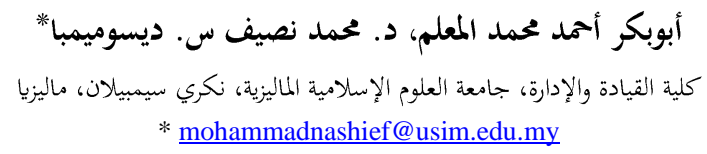

الكلمات المفتاحية الإدارة، المبادرات، كفاءة العمل.

Crossref doi https://doi.org/10.51345/.v32i3.448.g234

\section{ملخص البحث:}

ناقشت هذه الدراسة الكمية، دور إدارة المبادرات في تحسين كفاءة العمل لدى العاملين بشركة الميثانول في محافظة ظفار بسلطنة

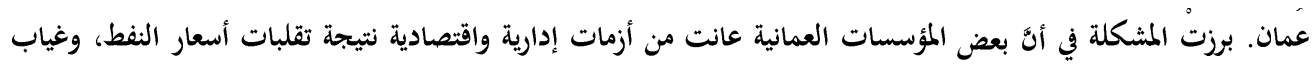

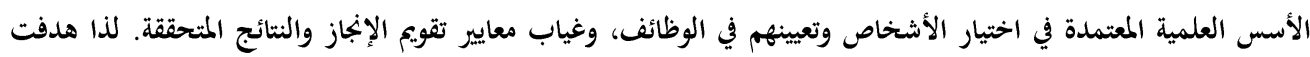

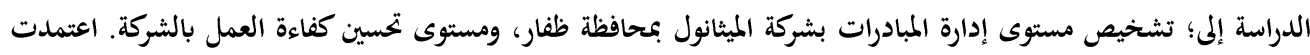

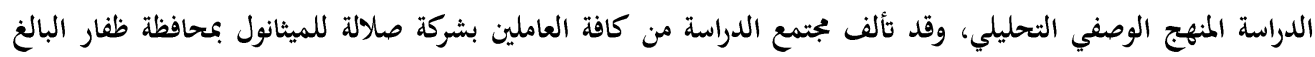

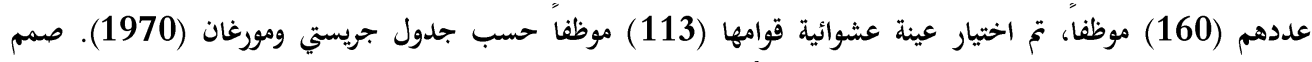

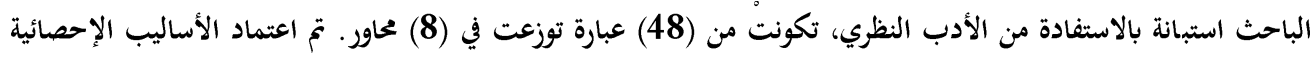

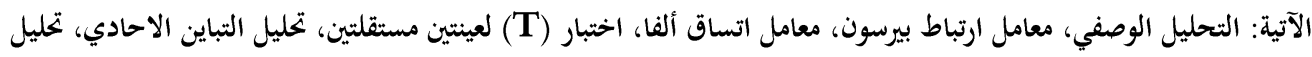

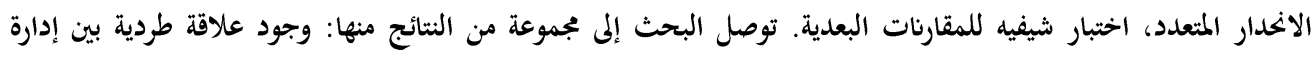

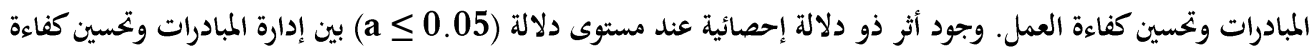

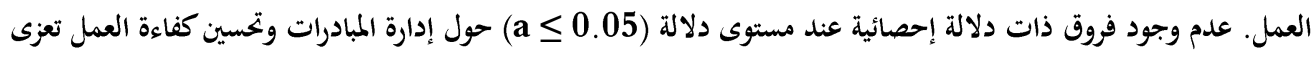

للمتغيرات الديمغرافية.

المقدمة:

المبادرة صفة إيجابية محمودة في الإنسان المبادر، لما يكون له من دور إيجابي فاعل في الحياة. وتعني المبادرة لغة

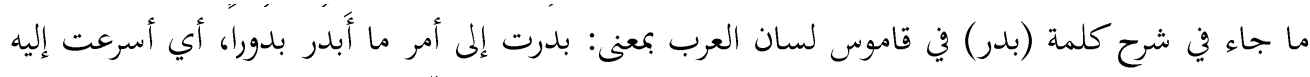

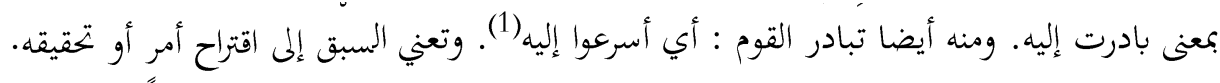




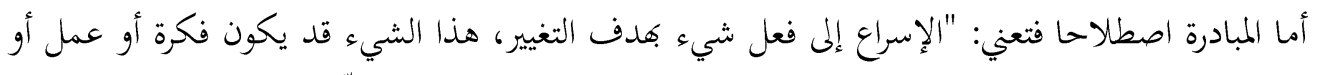

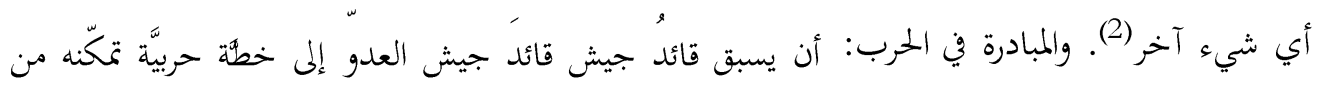

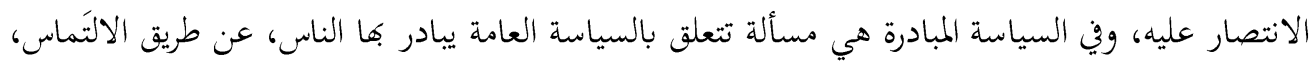

وتقرر عن طريق الاقتراع(3).

ثم تطور مفهوم المبادرة خلال السنوات الأخيرة، فأصبحت المبادرة؛ فكرة وخطة عمل تطرح لمعالجة قضايا

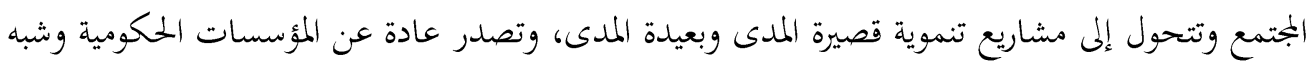

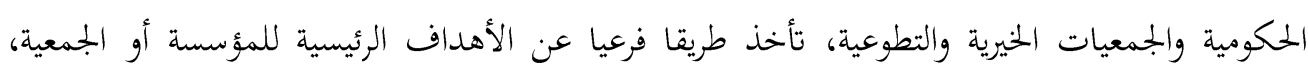
فتحقق أهدافها الفرعية بشكل مستقل.

وتعد" المبادرات أحدى الأساليب المهمة والضرورية لتطوير المنظمة وتنميتها، من خلال قيام أفراد المنظمة

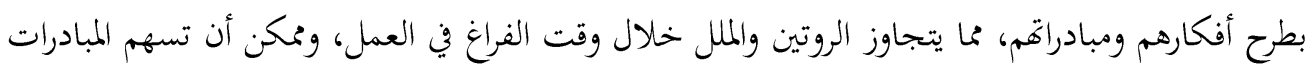

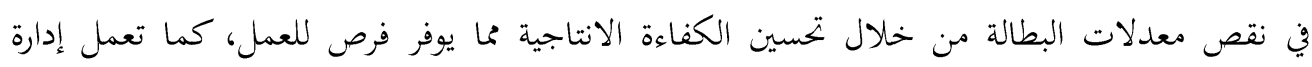

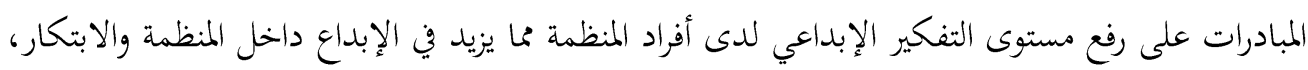

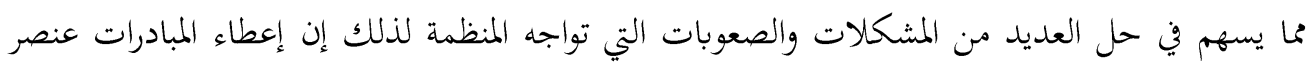

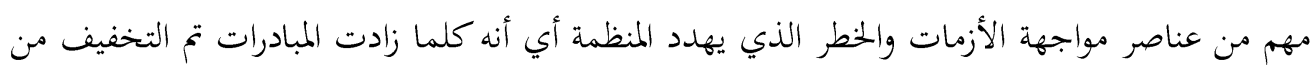
الوقع في الأزمات والمشاكل (4) مواصنمة الأمات وتمثل إدارة المعرفة حقلا علميا حديثا ولاسيما جانبه التطبيقي يعمل على توفير قدرات واسعة لمنظمات

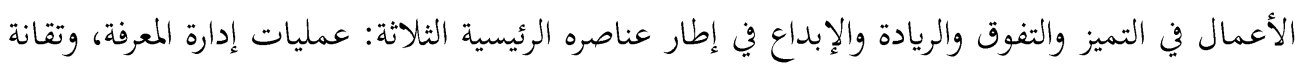
إدارة المعرفة، وفريق المعرفة(5).

\section{مشكلة الدراسة:}

تؤدي أنماط القيادة دورا كبيرا في بتسيد أدوار المدراء وقدراتم في إنجاز مهامهم واتخاذ القرارات المهمة، أو اعتماد جانب المرونة في مشاركة الموظفين ومساعدقم في إنجاز مهامهم ومسؤولياقم على أتم وجه (ياسين وبهرقافي، 2016). ومع ذلك نجد عديد من المؤسسات العمانية تعاني من أزمات إدارية واقتصادية نتيجة تقلبات أسعار النفط(6). وقد بينت نتائج العديد من الدراسات التي ناقشت أداء الموظفين في سلطنة عمان، ومنها ما خلصت له دراسة مسن (2018) في أن الأداء العام للمؤسسات العمانية، كغيرها من مؤسسات أخرى مماثلة؛ يعاني من غياب التشخيص الدقيق لمشكلات الإدارة؛ المتمثل في غياب الأسس العلمية المعتمدة في اختيار 
الأشخاص وتعيينهم في وظائف قيادية أو غير قيادية، إلى جانب غياب المعايير الخاصة بتقويم الإنجاز والنتائج المتحققة أو تلم التي لم تتحقق. كما بينت نتائج دراسة الغساتي (2006) التحديات والمعوقات التي ترافق دور المديرين في القيادة بالمؤسسات العمانية ولاسيما في القطاع الخاص، حين أشارت نتائج الدراسة إلى ممارسة القائد الإداري

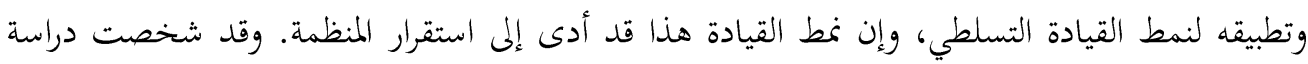
العكاري (2014)؛ وجود ضعف بائن في أداء وعمل المؤسسات الخندمية في القطاع العام بسلطنة عمان. حين شخصت وجود ضعف بشكل عام في الأداء العام الإداري والمالي، وضعف أداء العناصر الإدارية والمحاسبة، مما تسبب في فشو الترهل الإداري والمشاكل الاقتصادية، وقصور الخدمات العامة المجتمعية وتأخير إنجاز الطلبات.

\section{أهداف الدراسة:}

أ. تشخيص مستوى إدارة المبادرات بشركة الميثانول بمحافظة ظفار. ب. تحليل مستوى تحسين كفاءة العمل بشركة الميثانول بمحافظة ظفار.

\section{فرضية الدراسة:}

نصت الفرضية الصفرية على: "لا توجد علاقة ذات دلالة إحصائية عند مستوى دلالة (0,05) بين إدارة

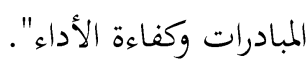

\section{الدراسات السابقة: - na} مقالة فرج، (2018) تقييم المبادرة المجتمعية "نو تعلم أفضل" بمحافظة أسوان. عرضت مشكلة التعليم

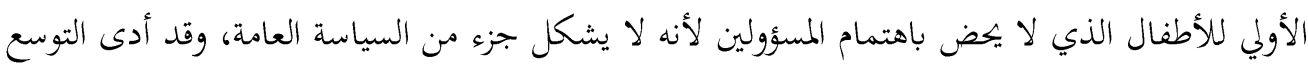
يي قبول أعداد كبيرة من الطلبة في التعليم الأساس إلى تدني جودة التعليم، إلى جانب اعتماد الأسلوب التقليدي في التدريس المبني على الحفظ والاسترجاع. لذلك بادرت جمعية "الجزويت والفرير" بتقديم مبادرة

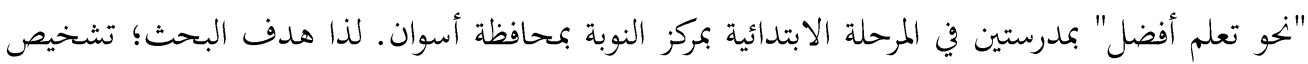

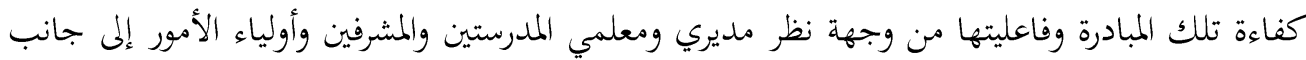
تشخيص سلبياتا وإيجابياتها. هدفت المبادرة: تمكين وحديت تدريب للقيام بدورها، تطوير أداد (13) معلما، تطوير أداء (7) مشرفات تربويات، زيادة التحصيل الدراسي لـ (100) تلميذ من ذوي المستوى الضعيف. شنملت المبادرة فتح دورة 
لتدريب المدربين (TOT)، فتح خمس دورات للمدرسين والمشرفين في مجال التعلم النشط، وقد اعتمدت الباحثة الأسلوب الكمي في جمع البيانات من خلال الاستبيان المعد، كما اعتمدت المنهج النوعي الذي تمثل في مقابلة مديري المدرستين والمعلمين والمشرفين و (25) سيدة من أولياء أمور الطالبة. إضافة إلى من إلى اعتماد أسلوب الملاحظة الذي طبق على (30) تلميذا في المدرستين. أفادت نتائج البحث، أنَّ المبادرة حققت أهدافها بالنسبة لتمكين وحدتي تدريب, وإن جميع المدرسين

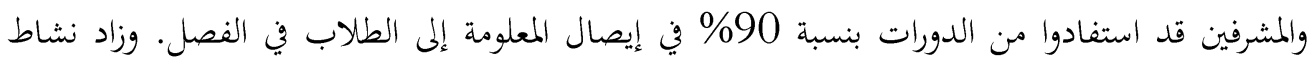
التلاميذ في الفصل بنسبة 80\%. كان تقييم أولياء الأمور للمبادرة؛ أفا كانت إيبابية ولها تأثير كبير وفعال إنسال على أداء الأطفال حين حققوا درجات (9و 10) بعد تطبيق المبادرة مقابل (2 إلى 4) قبل المبادرة، إضافة إلى التأثير الإيجابي لها على سلوكيات الأطفال، وزيادة الثقة بالنفس، واهتمامهم بالنظافة الشخصية. كما

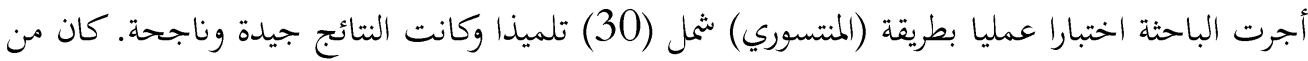
أبرز السلبيات؛ قلة عدد الطلاب المشمولين في المبادرة. مقال برباز، وكسار (2020) حول التقييم الاقتصادي لبعض مشروعات المبادرة الزراعية في العراق. هدف

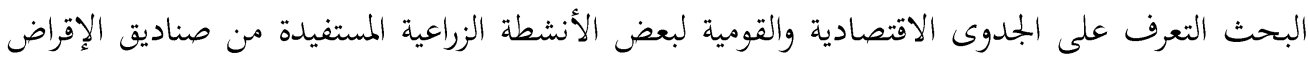

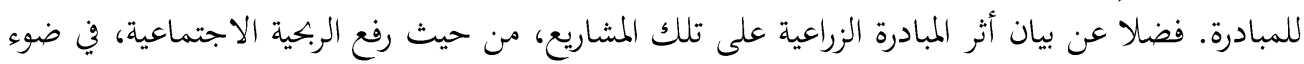
نتائج معايير التقييم القومية التي تناولها البحث. دللت النتائج على جودة مشروعات المبادرة الزراعية، حيث إلَّ جميع المشروعات المدروسة قد حققت صافي قيمة مضافة على مستوى الاقتصاد القومي. فقد سجل مشروع تربية أبقار الحليب أدنى قيمة صافية مضافة

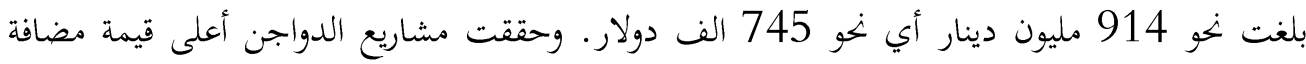
بلغت نحو 5 مليار دينار عراقي لمشاريع إنتاج بيض المائدة ونحو 9.4 مليار دينار لمشاريع فروج اللحم، هذا

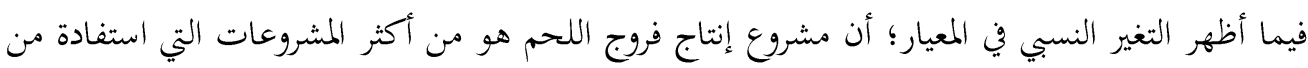

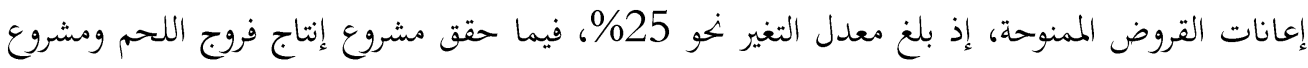
مفقس الدواجن ومشروع تربية أبقار الحليب معدل عائد اجتماعي سالب. واستطاعت إعانات المبادرة

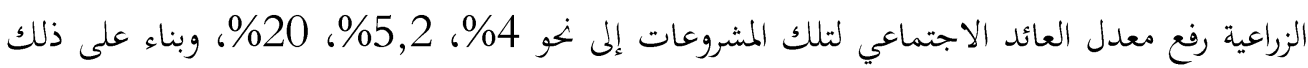
أوصى الباحث ضرورة استمرار دعم المشروعات الزراعية من الصناديق الإقراضية للمبادرة الزراعية لرفع الربحية القومية المشروعات الزراعية التي من شأها أن تسهم في عملية التنمية الزراعية في العراق. 
دراسة الفارس، (2010) بعنوان: دور إدارة المعرفة في رفع كفاءة أداء المنظمات دراسة ميدانية على شركات الصناعات التحويلية الخاصة بدمشق. هدفت التعرف على دور إدارة المعرفة في رفع كفاءة أداء المنظمات وتحسين مستوى الأداء وتعزيزه. اشتمل بجتمع البحث وعينته على عشر شركات حديثة أنشئت وفقا لقانون

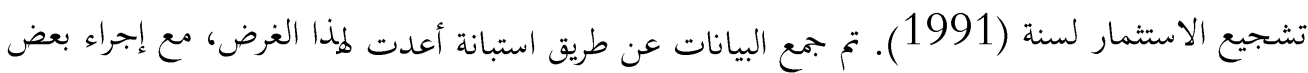

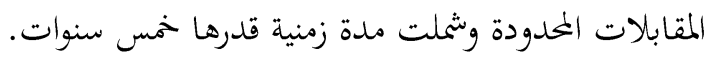
توصلت الدراسة إلى النتائج الآتية: لا تقوم الشركات موضع الدراسة بإعطاء قدر كاف من مات الحرية للعاملين، وبخاصة المختصين منهم، ولا تسعى لتعيين مديري معرفة جيدين. وجود علاقة ارتباط قوية ذات دلالة

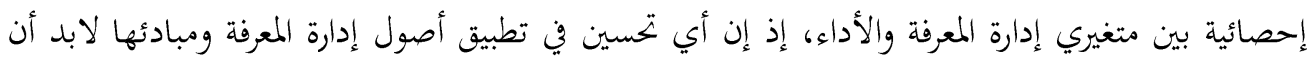
ينعكس إيجابا على رفع كفاءة الأداء. كما بينت وجود علاقة بين كل عنصر من عناصر إدارة المعرفة وبين كل محور من محاور الأداء.

دراسة محمد، (2008) المسؤولية الاجتماعية للشركات في ضوء المبادرات الدولية، هدفت الدراسة عرض المبادرات الجمتمعية التطوعية التي قدمت من قبل طلبة جامعة الأمير سطام بن عبد العزيز، خلال ثلاث

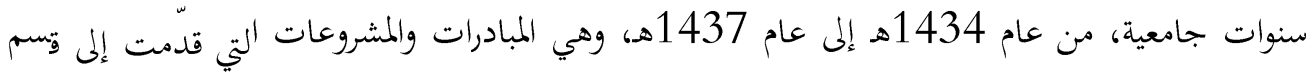
أمانة المؤتمر العلمي بعمادة شؤون الطلاب، للمنافسة في المسابقات العلمية الطلابية، ونفذت فئَ في الجمتمعات المحيطة بكلبات الجامعة في محافظات جنوب منطقة الرياض، وهي: الخرج والدلم وحوطة بني تميم والأفلاج

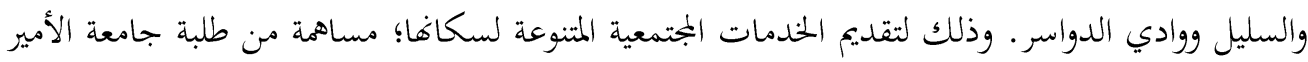
سطام ومنسوبيها في خدمة الجمتمع وتفعيل الشراكة المجتمعية. تم دراسة وتحليل عوامل القوة والضعف في تلك المبادرات، وأهم العقبات والتحديات التي واجهتها، والفرص والدوافع التي شجعت الطلاب على إقامتها، واقترح الباحث حلولا مناسبة لاستمرار المبادرات الجمتمعية الجيدة، وسبل الدعم والتبني لمثل هذه المبادرات من قبل إدارة الجامعة أو الجهات المختصة بالأنشطة والبرامج الطلابية بالجامعة، أو المؤسسات التطوعية والتجارة وغيرها، ووضح الباحث أثنيل أثر تلك المبادرات في تفعيل الشراكة المجتمعية للجامعة مع المجتمع ومؤسساته.

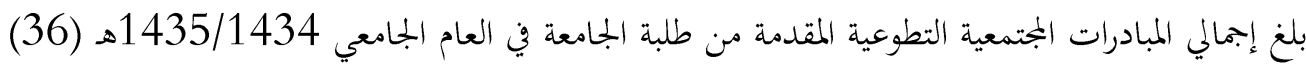

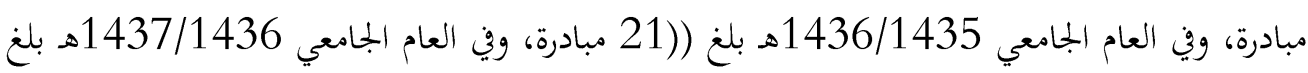
(26) مبادرة، وكان مجموع المبادرات للسنوات الثلاث (83) مبادرة، نفذت كلها ميدانيا. وبلغ إجمالي المبادرات المقدمة من الطلاب (33) مبادرة، ومن الطالبات (50) مبادرة، كما بلغ عدد المبادرات المقدمة 
من كليات التخصصات الصحية للطلاب (23) مبادرة ولطالبات (10)مبادرات. ومن كليات التخصصات الأساسية والهندسة: (6) مبادرات للطلاب و(11) مبادرة للطالبات. ومن كليات التخصصات الإنسانية والاجتماعية: (8) مبادرات للطلاب و (25) مبادرة للطالبات. واتضح من خلال استقراء المبادرات المعنية بالدراسة أن هناك إقبالا جيدا من قبل طلبة الجامعة على خدمة الجمتمع والبرامج التطوعية، حيث بلغ العدد الفعلي للطلبة المشاركين في البرامج والمبادرات الميدانية في السنوات الثناثة (275) طالبا وطالبة، وبلغ عدد الطلاب منهم (113) طالبا، وعدد الطالبات (162) طالبة. أما من حيث تصنيف المبادرات، فقد اتضح أن المجال الاجتماعي قدم فبه الطلاب البنين (4) مبادرات،

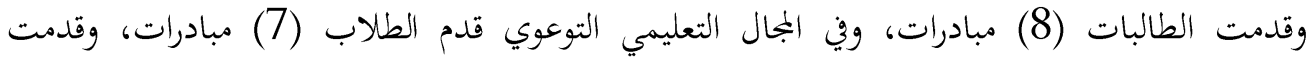
الطالبات (26) مبادرة. وفي المجال الصحي التوعوي قدم الطلاب (20) مبادرة وقدمت الطالبات (8) مبادرات. وفي الجمال التقني قدم الطلاب (4) مبادرات وقدمت الطالبات (مبادرتين). وفي المجال التقني التوعوي قدم الطلاب (3) مبادرات وقدمت الطالبات مبادرة واحدة. وتشير هذه الإحصاءات إلى تفوق جانب الطلاب في المجال الصحي التوعوي وهو مجال مهم جدا، وتفوقوا كذلك في الجمال التقني والتقني التوعوي. وتفوقت الطالبات في المجال الاجتماعي والبجال التعليمي التوعوي.

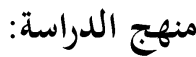

اتبع الباحث المنهج الوصفي التحليلي الذي يعتمد على المسح الميداني للحصول على البيانات من مصادرها

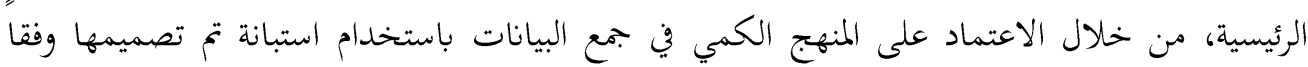
للخطوات العلمية التي اعتمدت.

\section{جمتمع الدراسة وعينتها:}

تألف مجتمع الدراسة من كافة العاملين بشركة صلالة للميثانول بمحافظة ظفار والبالغ عددهم (160)

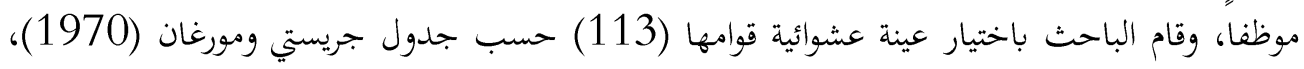
لإجراء التحليل الإحصائي.

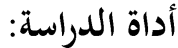

للحصول على البيانات المطلوبة، فقد صمم الباحث الاستبانة وفق تدرج مقياس (ليكرت) الخماسي، بالاستفادة من الأدب النظري في دراسات: الصرف (2005)؛ خيرالله (2009)؛ خصاونة (2011) 
بعد الأخذ بآراء أساتذة كلية العلوم الإدارية بجامعة ظفار. وتضمنت الاستبانة إضافة إلى البيانات الشخصية والوظيفية لعينة البحث، القسمين التاليين:

القسم الأول: يتكون من (37) فقرة توزعت على (7) محاور لقياس إدارة المبادرات.

القسم الثاني: واشتمل على محور تحسين كفاءة العمل، وقد تضمن هذا القسم (11) فقرة.

ويتم تفسير قيمة المتوسط الحسابي، لتحديد مستوى موافقة أفراد عينة البحث على فقرات ومحاور الاستبانة، بحسب الجدول الآتي:

جدول (1) المستويات المتحققة المقابلة ملميات المتوسطات الحسابية

\begin{tabular}{|c|c|c|c|c|c|}
\hline مرتفعة جدا & مرتفعة & متوسطة & منخفضة & منخفضة جلدا & الأهمية النسبية \\
\hline $5-4.21$ & $4.20-3.41$ & $3.40-2.61$ & $2.60-1.81$ & $1.80-1$ & المتوسط الحسابي \\
\hline
\end{tabular}

صدق الأداة وثبامَا:

الصدق الظاهري: - اه

تم اختبار الصدق الظاهري لأداة البحث بالاستعانة بعشرة المككمين من أعضاء الهيئة التدريسية والمتخصصين في مجالات إدارة الأعمال بجامعة ظفار، لأخذ آرائهم والاستفادة من ملاحظاتم في تعديل الاستبانة والخروج بها على صورثا النهائية الحالية، وقائمة الأساتذة المحكمين في ملحق البحث.

\section{ثبات الأداة:}

للتحقق من ثبات أداة البحث تم حساب معامل كرونباخ ألفا، من خلال التطبيق لمرتين على عينة قدرها (30) موظفاً من خارج عينة الدراسة، للتأكد من ثبات أداة القياس لكون الاستبانة تقيس العوامل المراد قياسها والتثبت من صدقها، وذلك عائد لطبيعة معامل كرونباخ ألفا في قياسه للاتساق الداخلي لفقرات القياس، وهذا يعني قوة الارتباط والتماسك بين فقرات القياس، إضافة إلى ذلك فإن معامل ألفا يعطى بتقدير جيد للثبات. وقد بلغت قيمة الفا للاستبانة الكلية (0,86) وهى نسبة مرتفعة وأعلى من المعدل المقبول (0,6)، وهذا يدل على امكانية ثبات النتائج التي يمكن أن تترتب عند تطبيق الاستبانة. والجدول (2) يوضح قيمة معامل كرونباخ الفا لمتغيرات البحث. 


\begin{tabular}{|c|c|c|}
\hline معامل ثبات (كرونباخ الفا) & الغلحاور & ت \\
\hline .858 & وجود أهداف واضحة & .1 \\
\hline .836 & البيئة المحيطة بالعمل & .2 \\
\hline .843 & التشجيع على الإبداع والابتكار & .3 \\
\hline .855 & طبيعة العمل & 4 \\
\hline .851 & التفاعل أثناء العمل & .5 \\
\hline .830 & إدراك قيمة المبادرة & 6 \\
\hline .835 & القيادة المهتمة بالعاملين & .7 \\
\hline .830 & تحسين كفاءة العمل & .8 \\
\hline .860 & الاستبانة ككل & \\
\hline
\end{tabular}

أساليب المعالجة الإحصائية:

لتحقيق أهداف البحث، تم استخدام برنامج الحزمة الإحصائية للعلوم الاجتماعية Version22) SPSS) في المعالجة الإحصائية، وتم استخدام أساليب التحليل الإحصائية الآتية: أ. التحليل الوصفي لاستخراج التكرارات، والمتوسطات الحسابية والانحرافات المعيارية لاستجابات عينة البحث على محاور الاستبانة. ب. معامل ارتباط بيرسون لقياس قوة وطبيعة العلاقة بين المتغيرات المستقلة والمتغير التابع. ت. معامل ألفا للاتساق الداخلي. ث. اختبار (T) لعينتين مستقلتين حسب متغير النوع الاجتماعي. ج. تحليل التباين الاحادي لاختبار الفروقات لاستجابات محاور البحث حسب المتغيرات الشخصية. ح. تحليل الانحدار المتعدد لقياس تأثير المتغيرات المستقلة على المتغير التابع. 
خ. اختبار شيفيه للمقارنات البعدية عند وجود فروق للاستجابات في محاور البحث حسب المتغيرات الشخصية عدا متغير النوع.

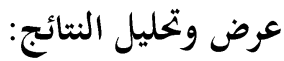

\section{تحليل إجابة السؤال الأول:}

نص السؤال الأول على ما يلي: "ما مستوى إدارة المبادرات بشركة الميثانول بمحافظة ظفار؟" للإجابة عن هذا السؤال، قام الباحث بحساب المتوسطات الحسابية والانخرافات المعيارية ومستوى الموافقة لاستجابات عينة البحث على متغيرات إدارة المبادرات ومحاورها، وتم ترتيب الفقرات وفقا للمتوسط الحساباني.

\section{أولا . عحور وجود أهداف واضحة:}

جدول (3) نتائج تحليل فقرات محور وجود أهداف واضحة

\begin{tabular}{|c|c|c|c|c|c|}
\hline 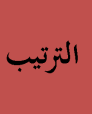 & الأهمية & الانغراو & المتوسط الحسابي & الفقرات & ت \\
\hline 1 & مرتفعة جلدا & 0,542 & 4,33 & تعد أهداف المنظمة معروفة لي. & .1 \\
\hline 2 & 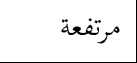 & 0,546 & 4,20 & أتمكن من تحديد أهدافها بسهولة ويسر. & .2 \\
\hline 3 & 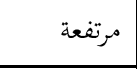 & 0,7 & 4,13 & لا تتعارض أهدافي مع أهداف المنظمة. & .3 \\
\hline 4 & مرتفعة & 0,746 & 4,05 & تنشر المنظمة أهدافها بشكل واضح للعاملين. & .4 \\
\hline 5 & مرتفعة & 0,803 & 4 & تتضمن أهداف المنظمة عبارات محفزة ومشجعة. & .5 \\
\hline & مرتفعة & 0,43 & 4,14 & \multicolumn{2}{|c|}{ المتوسط العام } \\
\hline
\end{tabular}

تشير نتائج الجدول (3) أن مستويات استجابات أفراد عينة البحث لوجود أهداف واضحة بالشركة

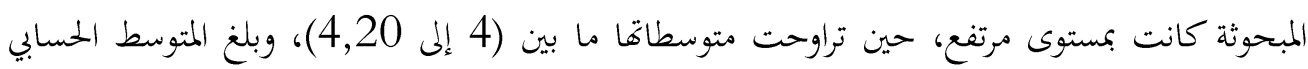

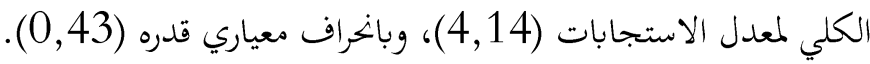

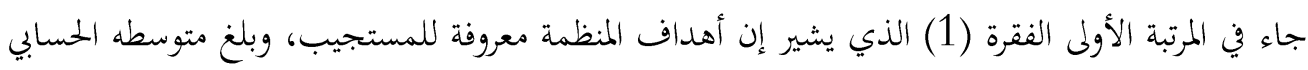
(4.33). وفي المرتبة الثانية جاء مضمون الفقرة (2) المتعلق بتمكن المستجيب من تحديد أهداف المنظمة المناء بسهولة ويسر، بمتوسط حسابي (4,2)، وفي المرتبة الثالثة جاءت الفقرة (3) بشأن عدم تعارض أهداف 
المستجيب مع أهداف المنظمة بمتوسط حسابي بلغ (4.13)، وكانت المرتبة الأخيرة للفقرة (5) الذي ينص على أن أهداف المنظمة تتضمن عبارات محفزة ومشجعة للمستجيب، بأدنى متوسط حسابي بلغ (4.00). ثانيا. محور البيئة الخيطة بالعمل: جدول (4) نتائج تحليل فقرات محور البيئة المخيطة بالعمل

\begin{tabular}{|c|c|c|c|c|c|}
\hline الترتيب & الأهمية & الالمعراف & المتوسط المسبي & 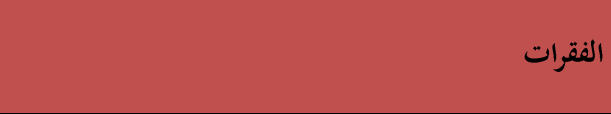 & ت \\
\hline 3 & مرتفعة & 0,892 & 4,02 & تعتمد المنظمة على فرق العمل في انجاز الأعمال. & .6 \\
\hline 2 & مرتفعة & 0,701 & 4,18 & تسود روح التعاون والعلاقات الطيبة بيني وبين زملائي في & .7 \\
\hline 5 & مرتفعة & 0,833 & 3,87 & توفر المنظمة كافة الامكانات المادية والتكنولوجية للنهوض & .8 \\
\hline 4 & مرتفعة & 0,872 & 3,95 & توفر المنظمة برامج تدريب حديثة ومناسبة لي. & .9 \\
\hline 1 & مرتفعة & 0,676 & 4,18 & يسود شعور إيجابي لدي حول طريقة إنجاز المهام في المنظمة. & 10 \\
\hline & مرتفعة & 0,48 & 4,04 & \multicolumn{2}{|c|}{ المتوسط العام } \\
\hline
\end{tabular}

تشير نتائج الجدول (4) أن مستويات الاستجابة لمور البيئة المحيطة بالعمل كانت بمستوى مرتفع، تراوحت متوسطاكا ما بين (3,87 إلى 4,18)، حيث بلغ المتوسط الحسابي الكلي لمعدل الاستجابات (4,04)، وبانحراف معياري قدره (0.48). وقد جاءت في المرتبة الأولى الفقرة (10) الذي يشير إلى سيادة الشعور الايجابي لدى المستجيب حول طريقة انجاز المهام في المنظمة، بمتوسط حسابي (4,18). ووفي المرتبة الثانية جاءت الفقرة (7) سيادة روح التعاون والعلاقات الطيبة بين المستجيبين في المنظمة، بمتوسط حسابي (4,18) أيضا، وفي المرتبة الثالثة الفقرة (6) اعتماد المنظمة على فرق العمل في ابجاز الأعمال بمتوسط (4,02). وكانت المرتبة الأخيرة للفقرة (8) توفر المنظمة كافة الامكانات المادية والتكنولوجية للنهوض بالعمل، بأدنى متوسط حسابي بلغ . $(3,87)$ 


\section{ثالثا. محور تشجيع الإبداع:}

جدول (5) يبين نتائج تحليل فقرات محور التشجيع على الإبداع

\begin{tabular}{r|r|r|r|r|r}
\hline \\
\hline
\end{tabular}

يبين الجدول (5) أن استجابات العينة لمحور التشجيع على الإبداع كانت بمستوى مرتفع، تراوحت متوسطاتها ما بين (3,88 إلى 4,20)، حيث بلغ المتوسط الحسابي الكلي لمعدل الاستجابات (3,97)، وبانحراف معياري قدره (0,44). جاءت في المرتبة الأولى الفقرة (11) سيادة روح التشجيع على الإبداع كاطار للعمل في المنظمة، بمتوسط

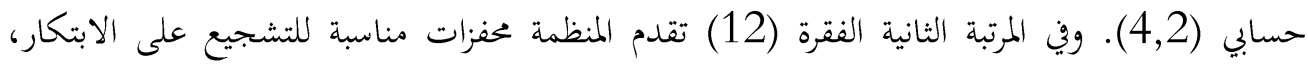

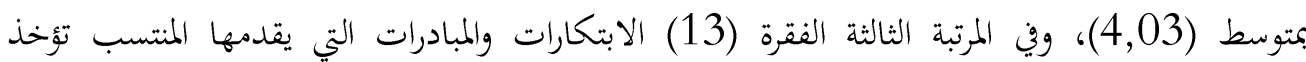
بالاعتبار بمتوسط حسابي (3,95)، وكانت المرتبة الأخيرة للفقرة (14) المنظمة تنفذ معظم المبادرات التي قدمتها، بأدنى متوسط حسابي بلغ (3,83).

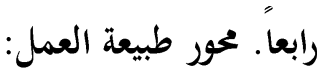

تشير نتائج الجدول (6) أن مستويات استجابات محور طبيعة العمل بالشركة، كانت بمستوى مرتفع، تراوحت متوسطاها ما بين (3,87 إلى 4,35)، حيث بلغ المتوسط الحسابي الكلي لمعدل الاستجابات

$$
\text { (4,13)، وبانحراف معياري قدره (0,45). }
$$


جدول (6) نتائج تحليل فقرات محور طبيعة العمل

\begin{tabular}{|c|c|c|c|c|c|}
\hline الترتيب & الأهمية النسبية & الالانراف & المتوسط المسابي & 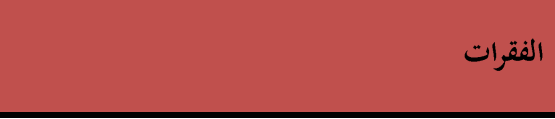 & $ت$ \\
\hline 1 & مرتفعة جدا & 0,633 & 4,35 & تثا. تثري الوظيفة عملي بشكل جيد عندما أكون مرتبطا & .17 \\
\hline 2 & مرتفعة جلدا & 0,696 & 4,3 & تقدم الوظيفة لي مزيدا من الحبرات والمهارات. & .18 \\
\hline 3 & مرتفعة & 0,659 & 4,15 & أشعر بأني أسيطر على وظيفتي بشكل جيد. & 19 \\
\hline 4 & 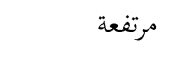 & 0,689 & 4 & تعد الوظيفة التي أقوم بها متجددة بشكل مستمر. & .20 \\
\hline 5 & مرتفعة & 0,892 & 3,87 & أشعر بان وظيفتي تحقق لي إشباعاً مهماً. & .21 \\
\hline & مرتفعة & 0,45 & 4,13 & \multicolumn{2}{|c|}{ لمتوسط العام } \\
\hline
\end{tabular}

حلت بالمرتبة الأولى الفقرة (17) الوظيفة تثري عملي بشكل جيد عندما أكون مرتبطا بها، بمتوسط حسابي

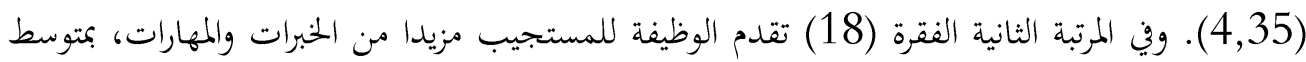

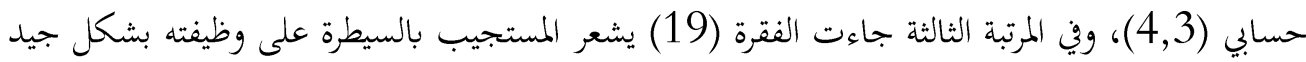
بمتوسط (4,15). وحلت بالمرتبة الأخيرة الفقرة (21) الوظيفة التي يقوم بها المستجيب تشعره بتحقيق

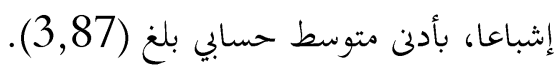

\section{خامساً. محور الثفاعل أثناء العمل:}

تشير نتائج الجدول (7) أن مستويات استجابات العينة في محور التفاعل أثناء العمل بالشركة كانت بمستوى مرتفع، تراوحت المتوسطات ما بين (3,83 إلى 4,37)، وقد بلغ المتوسط الحسابي الكلي لمعدل الاستجابات (4,07)، وبانحراف معياري قدره (0,43). حلت في المرتبة الأولى الفقرة (22) تبادل الحوار والنصيحة بين الموظفين أثناء العمل، بمتوسط حسابي (4,37). وفي المرتبة الثانية جاءت الفقرة (23) المتعلق بتشجيع المنظمة على اتصال العاملين مع بعض، بمتوسط حسابي (4,15). في حين جاءت الفقرة (24) بالمرتبة الثالثة: تصمم المنظمة وظائفها بشكل يسمح بالتفاعل بين المستجيب وزملائه بمتوسط بلغ (4,02). وفي المرتبة الأخيرة حلت الفقرة (25) تقيم المنظمة ندوات وورش عمل يكضرها الموظفون بشكل مستمر، حازت على أدنى متوسط حسابي بلغ 
جدول (7) نتائج تحليل فقرات محور الثفاعل أثناء العمل

\begin{tabular}{|c|c|c|c|c|c|}
\hline الترتيب & الأهمية النسبية & 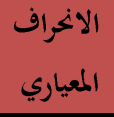 & المتوسط & 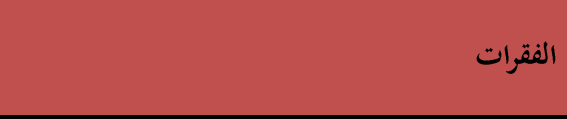 & ت \\
\hline 1 & مرتفعة جدا & 0,688 & 4,37 & أتبادل الحوار والنصيحة مع زملائي أثناء العمل & .22 \\
\hline 2 & 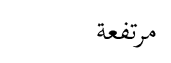 & 0,755 & 4,15 & تشجع المنظمة على اتصال العاملين مع بعض. & .23 \\
\hline 3 & 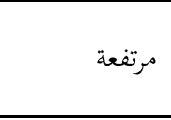 & 0,725 & 4,02 & زملائي. المنظمة وظائفها بشكل يسمح بالثفاعل بيني وبين & .24 \\
\hline 5 & 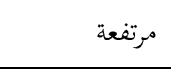 & 0,886 & 3,83 & تقيم المنظمة ورش عمل أحضرها باستمرار. & .25 \\
\hline 4 & 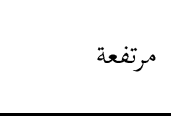 & 0,712 & 3,97 & تقتد انظمة الاتصال في المنظمة في كل الاتحاهات ولا & .26 \\
\hline & 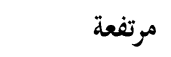 & 0,43 & 4,07 & \multicolumn{2}{|c|}{ المتوسط العام الم } \\
\hline
\end{tabular}

\section{سادساً. محور إدراك قيمة المبادرة:}

جدول (8) نتائج تحليل فقرات محور إدراك قيمة المبادرة

\begin{tabular}{|c|c|c|c|c|c|}
\hline الترتيب & الأهمية & الانمراف & المتوسط & الفقرات & ت \\
\hline 1 & 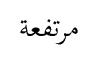 & 0,843 & 4,03 & تدعم إدارة المنظمة المبادرات المقدمة من قبلي. & .27 \\
\hline 2 & 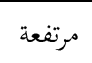 & 0,725 & 4,02 & تعزز إدارة المنظمة المبادرات المقدمة من قبلي بالمزيد من البحث. & .28 \\
\hline 4 & مرتفعة & 0,72 & 3,92 & تكافئ المنظمة اصحاب المبادرات وتدعو الآخرين لتقديم & .29 \\
\hline 5 & 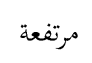 & 0,817 & 3,9 & تؤمن المنظمة بان كل مبادرة تستحق النقاش والثناء. & .30 \\
\hline 3 & 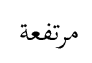 & 0,756 & 3,93 & تسهل المنظمة تطبيق المبادرة على أرض الواقع. & .31 \\
\hline & 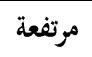 & 0,48 & 3,96 & \multicolumn{2}{|c|}{ المتوسط العام } \\
\hline
\end{tabular}

يبين الجدول (8) أن مستويات استجابات أفراد عينة البحث لمحور إدراك قيمة المبادرة بالشركة كانت بمستوى مرتفع، تراوحت المتوسطات ما بين (3,9 إلى 4,03)، حيث بلغ المتوسط الحسابي الكلي لمعدل

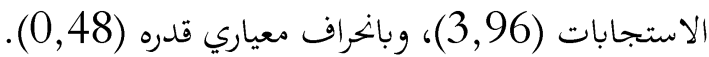
فقد جاءت أولا الفقرة (27) دعم إدارة المنظمة للمبادرات المقدمة من قبل المنتسب، بمتوسط حسابي

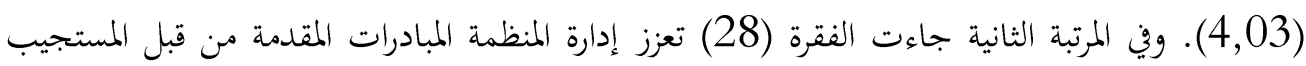


بمزيد من البحث بمتوسط حسابي (4,02). وفي المرتبة الثالثة حلت الفقرة (31) تسهل المنظمة تطبيق

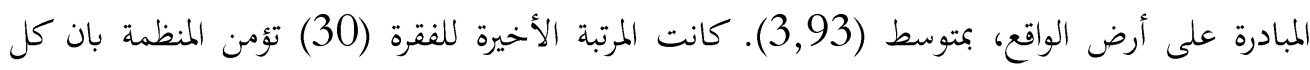

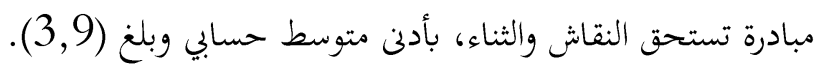

\section{سابعاً. محور القيادة المهتمة بالعاملين:}

جدول (9) نتائج تحليل فقرات محور القيادة المهتمة بالعاملين

\begin{tabular}{|c|c|c|c|c|c|}
\hline 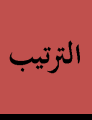 & 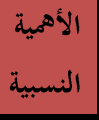 & الانمراف & المتوسط & 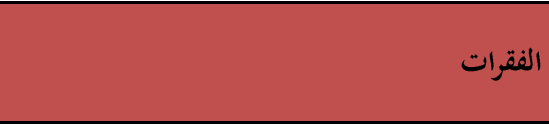 & ت \\
\hline 1 & 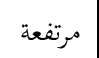 & 0,567 & 4,18 & تعزز الإدارة شعوري بالمسؤولية. & .32 \\
\hline 2 & 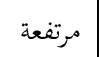 & 0,882 & 4,03 & تحرص الإدارة على تبني قضايا العاملين. & .33 \\
\hline 5 & مرتفعة & 0,8 & 3,93 & تشارك الإدارة في المناسبات الاجتماعية للعاملين. & .34 \\
\hline 6 & 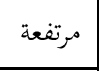 & 0,917 & 3,85 & تتيح الإدارة للعاملين بجالا للتفكير والإبدع. & .35 \\
\hline 4 & 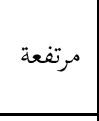 & 0,811 & 3,95 & تعقق الإدارة رضا العاملين وتزيد من تماسك فرق & .36 \\
\hline 3 & 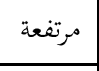 & 0,843 & 4,03 & توحد الإدارة جهد العاملين وتخثهم على التغيير. & .37 \\
\hline & 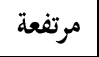 & 0,516 & 4 & \multicolumn{2}{|c|}{ المتوسط العام } \\
\hline
\end{tabular}

تشير نتائج جدول (9) إلى أن مستويات استجابات أفراد عينة البحث لمور القيادة المهتمة بالعاملين بالشركة المبحوثة كانت بمستوى مرتفع، حيث بلغ المتوسط الحسابي الكلي لمعدل الاستجابات (4)، وبانحراف معياري قدره (0,52).

جاءت في المرتبة الأولى الفقرة (32) الإدارة تعزز شعور المستجيب بالمسؤولية، بمتوسط حسابي (U23) (4,18.

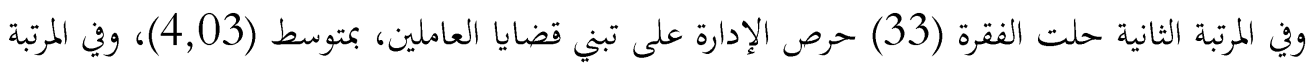
الثالثة الفقرة (37) توحد الإدارة جهود العاملين وتحثهم على التغيير، كان بمتوسط حسابي (4,03) أيضا.

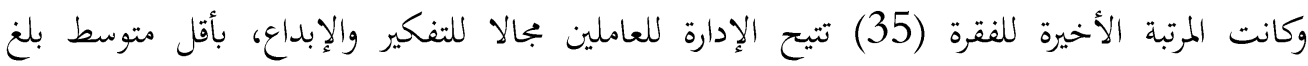

نص السؤال الثاني على: "ما مستوى تحسين كفاءة العمل بشركة الميثانول بمحافظة ظفار؟" 
للإججابة عن السؤال قام الباحث بحساب المتوسطات الحسابية والانحرافات المعيارية ومستوى الموافقة لاستجابات عينة البحث على متغيرات تحسين كفاءة العمل وفقراتما، وتم ترتيب الفقرات وفقا لمتوسطاتًا الحسابية.

جدول (10) نتائج تحليل فقرات محور تحسين كفاءة العمل

\begin{tabular}{|c|c|c|c|c|c|}
\hline الترتيب & 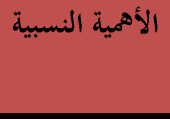 & المعياري - الانمراف & المتوسط & 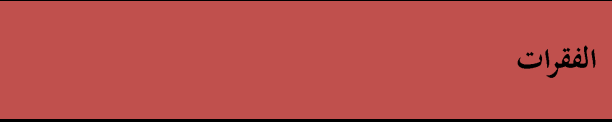 & ت \\
\hline 1 & مرتفعة جدا & 0,691 & 4,38 & تستخدم المنظمة تكنولوجيا متطورة. & .1 \\
\hline 4 & مرتفعة & 0,829 & 4,08 & تُحدث المنظمة مواردها بشكل مستمر. & .2 \\
\hline 11 & 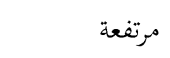 & 0,932 & 3,75 & يلاحظ وجود انخفاض في قيمة الموارد المهدرة في المنظمة & .3 \\
\hline 10 & مرتفعة & 0,789 & 3,77 & يوجد تحسن ملحوظ في رضا العاملين في المنظمة. & .4 \\
\hline 7 & مرتفعة & 0,736 & 4 & تتخذ المنظمة قرارات مفيدة ومهمة لمستقبلها. & .5 \\
\hline 6 & مرتفعة & 0,852 & 4,05 & يوجد تحسن ملحوظ في علاقة المنظمة بزبائنها. & .6 \\
\hline 9 & مرتفعة & 0,88 & 3,85 & تعتمد المنظمة على التخصص في إسناد الأعمال للعاملين & .7 \\
\hline 8 & 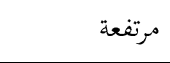 & 0,696 & 3,92 & يوجد الخفاض نسبي في الأخطاء التي يقع فيها الموظفون. & .8 \\
\hline 5 & 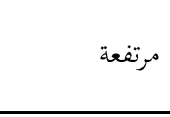 & 0,79 & 4,05 & ترتبط باحظ تحسن أداء العاملين الذين اشتركوا في دورات تدريبية & .9 \\
\hline 2 & مرتفعة جدا & 0,715 & 4,22 & تقدم المنظمة خدمتها ومنتجاتها بجودة مناسبة. & .10 \\
\hline 3 & مرتفعة جدا & 0,885 & 4,22 & تقدم المنظمة خدماتما في الوقت المناسب الى الاسواق. & .11 \\
\hline & 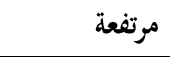 & 0,44 & 4,03 & \multicolumn{2}{|c|}{ المتوسط العام } \\
\hline
\end{tabular}

تشير نتائج الجدول (10) أن مستويات استجابات أفراد عينة البحث لمحور تحسين كفاءة العمل بالشكة

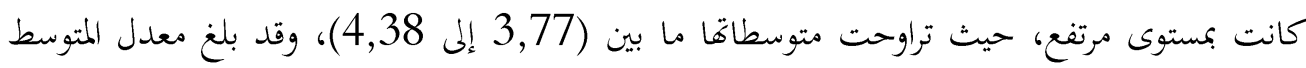

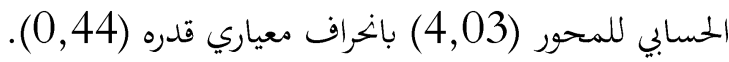
حازت الفقرة (1) تستخدم المنظمة تكنولوجية متطورة، على أعلى درجات الموافقة، حيث بلغ المتوسط

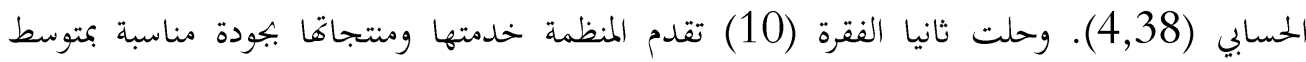
(4,22). وجاءت الفقرة (11) بالمرتبة الثالثة بمتوسط (4,22) أيضاً. في حين نالت الفقرة (3) انخفاض وحنداض 
الموارد المهدرة في المنظمة، على أدنى درجات الموافقة من وجهة نظر أفراد العينة بمتوسط حسابي قدره

\section{عرض وتحليل نتائج اختبار فرضية الدراسة: تحليل اختبار الفرضية:}

نصت الفرضية على: "لا توجد علاقة ذات دلالة إحصائية عند مستوى دلالة (0,05) بين إدارة المبادرات وكفاءة الأداء".

ولاختبار هذه الفرضية قام الباحث بحساب معامل ارتباط بيرسون لإيجاد واختبار قوة العلاقة وطبيعتها لدرجة استجابات العينة لماور إدارة المبادرات ودرجة كفاءة العمل، وإيجاد واختبار قوة العلاقة وطبيعتها للدرجة الكلية لاستجابات عينة البحث لإدارة المبادرات ودرجة كفاءة العمل.

جدول (11) نتائج اختبار العلاقة بين إدارة المبادرات وكفاءة الأداء

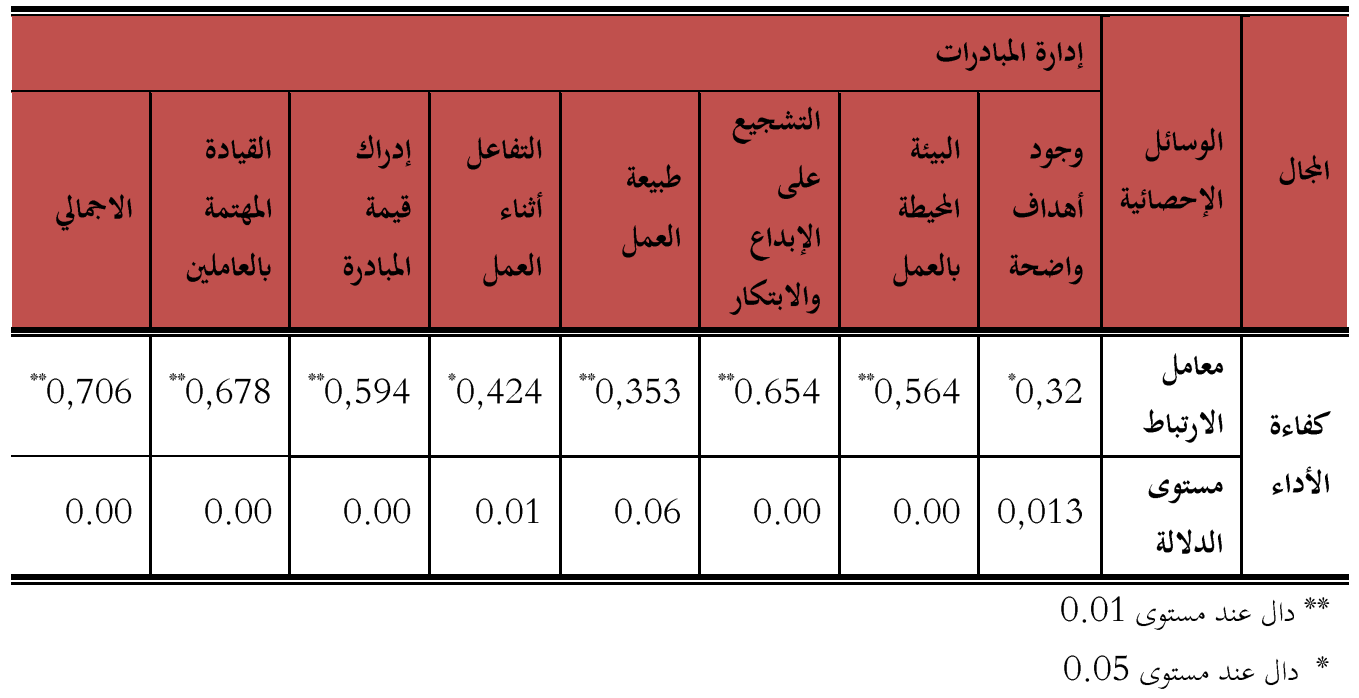

يبين الجدول (11) أن معامل الارتباط بين وجود أهداف واضحة وكفاءة الأداء قد بلغ (0,32) وكانت الدلالة الإحصائية المصاحبة لها تساوى (0,013)، وهي أقل من مستوى الدلالة الإحصائية (0,05)،

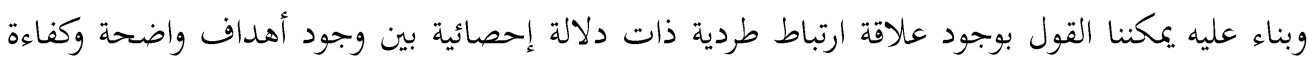
الأداء. بمعنى أنه كلما كانت الأهداف واضحة كلما تحسنت كفاءة العمل. واتضح كذلك أن معامل 
الارتباط بين البيئة المحيطة بالعمل وكفاءة الأداء قد بلغ (0,564) وكانت الدلالة الإحصائية المصاحبة لها

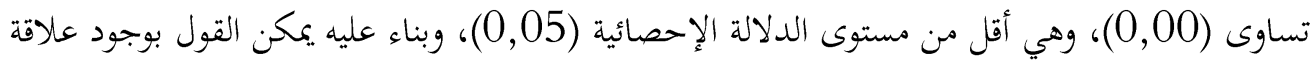
ارتباط طردية وذات دلالة إحصائية بين البيئة المحيطة بالعمل وكفاءة الأداء. بمعنى أنه كلما كانت البيئة المخيطة بالعمل جيدة كلما تحسنت كفاءة العمل. أما الدلالة الإحصائية بين التشجيع على الإبداع والابتكار وكفاءة العمل فقد كانت تساوى (0,00)، ويمكن القول بوجود علاقة ارتباط طردية ذات دلالة الإه إحصائية بين التشجيع على الإبداع والابتكار وكفاءة الأداء. بمعنى كلما زاد التشجيع على الإبداع والابتكار كلما تحسنت كفاءة العمل. واتضح كذلك وجود دلالة إحصائية بين طبيعة العمل وكفاءة الأداء قد بلغت مستوى (0,05)، ويمكن القول بوجود علاقة ارتباط إحصائية بين طبيعة العمل وكفاءة الأداء.

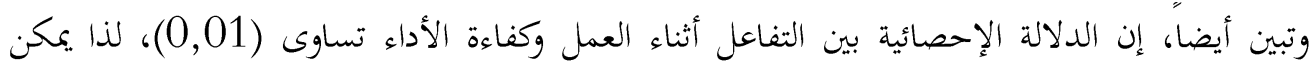
القول بوجود علاقة ارتباط طردية ذات دلالة إحصائية بين التفاعل أثناء العمل اكفاءة الأداء. واتضح

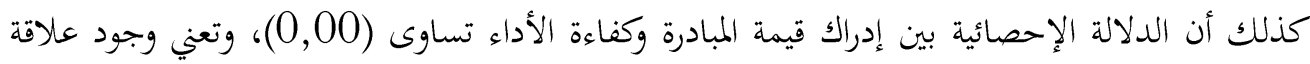
ارتباط طردية ذات دلالة إحصائية. كذلك علاقة الارتباط بين القيادة المهتمة بالعاملين وكفاءة العمل كانت الدلالة الإحصائية تساوى (0,00)، وتعني وجود علاقة ارتباط طردية ذات دلالة إحصائية بين القيادة

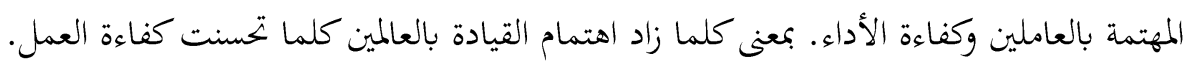
ولأجل اختبار فرضية البحث الرئيسة الاولى وجد أن معامل الارتباط بين مجمل محاور إدارة المبادرات وكفاءة

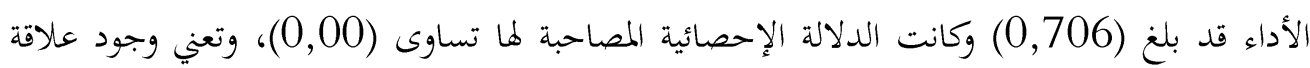
ارتباط طردية ذات دلالة إحصائية بين إدارة المبادرات وكفاءة الأداء. بمعنى كلما زادت إدارة المبادرات ذات مستوى عال كلما كان هناك تحسن بمستوى كفاءة العمل. ومن خلال النتائج اعلاه فأننا نرفض الفرضية الصغرية "بعدم وجود علاقة ذات دلالة إحصائية عند مستوى

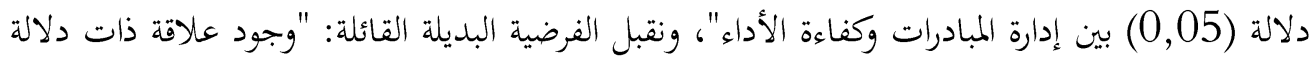
إحصائية عند مستوى دلالة (0,05) بين إدارة المبادرات وكفاءة الأداء".

التوصيات: يوصي البحث بما يأتي: أ. . ضرورة قيام الشركة بوضع أهداف واضحة يسهل على العاملين التعرف عليها وفهمها.

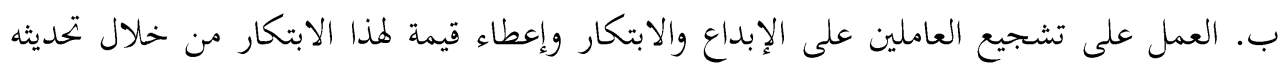
وتطبيقه على أرض الواقع. 


\section{ت. العمل على اشراك العاملين بدورات تدريبية لرفع من كفاءةم ومهاراتم.}

ث. الاهتمام بقضايا العاملين وبمشاركتهم في حلها إلى جانب مشاركة العاملين في مناسباتم الاجتماعية.

المصادر :

1

2. البلاوي، حسن. 1995. إدارة الجودة الشاملة في التعليم العالي بكصر. ورقه عمل مقدمة إلى مؤتمر التعليم العالي وتحديات القرن (21)، القاهرة: مركز

اعداد القادة.

برباز، ضرغام وكسار، علي. (2020). التقييم الاقتصادي لبعض مشروعات المبادرة الزراعية في العراق. مجلة العلوم الزراعية العراقية، (3) 51، ص

$804-797$ 4. 5.

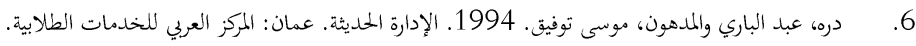

7.

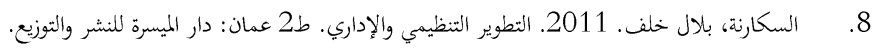

9.

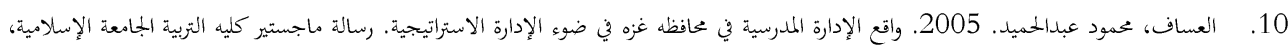

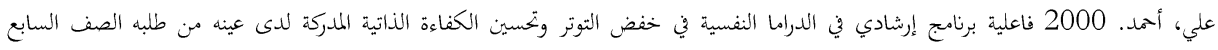

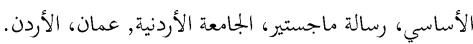

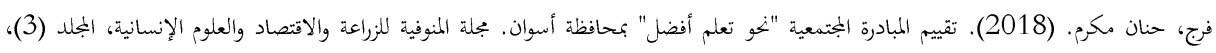

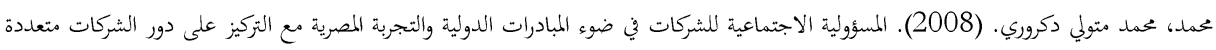

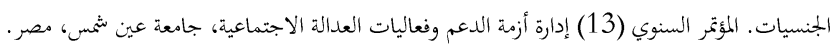

96 1963 (1) (1)

(2) خضير، خرشة، 2007: 23 (1) 23

(3) ويكيبيديا، مبادرة خضير، خرشة

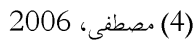

(5) الفارس، (5) مصنى، (5) 2010

(6) تقرير خطة عمان، 2020 (5) 